\title{
Reconciliation in health care must go beyond cultural sensitivity
}

\author{
n Cite as: CMAJ 2021 February 16;193:E256-7. doi: 10.1503/cmaj.1095919
}

Posted on cmajnews.com on January 29, 2021

$\mathbf{F}$

ive years after Canada's Truth and Reconciliation Commission issued calls to action, and 12 years after health care workers ignored Brian Sinclair as he died in a Winnipeg emergency department, the death of Joyce Echaquan last fall underscored how unsafe hospitals remain for many Indigenous people.

As Echaquan live-streamed the abuse she experienced at the Centre Hospitalier de Lanaudière in the hours leading up to her death, at another Quebec hospital 400 km away, Georges-Hervé Awashish of the Atikamekw Nation reportedly overheard staff laughing about her. He later died in hospital, six days after telling reporters he was afraid he would suffer the same fate as Echaquan.

"We hear stories far too often about Indigenous people experiencing racism in the health care system," said Renee Linklater, a member of Rainy River First Nations in Northwestern Ontario, at the Indigenous Health Conference in Toronto.

Such stories are just the latest incidents in a long history of racist abuse in health care, from the Inuit sanatoriums of the 1940 s to the forced sterilization of Indigenous women as recently as 2018 . And for every incident reported by the media, many more likely "go under the radar," Linklater said.

Cultural sensitivity training for health care providers is a good starting point for reconciliation, Linklater told CMAJ. These initiatives set a standard for everyone who works in the health system, she said. But the problem goes beyond the biases of individual front-line workers, and the solutions should too.

Linklater is the senior director of Shkaabe Makwa, Canada's first hospital-

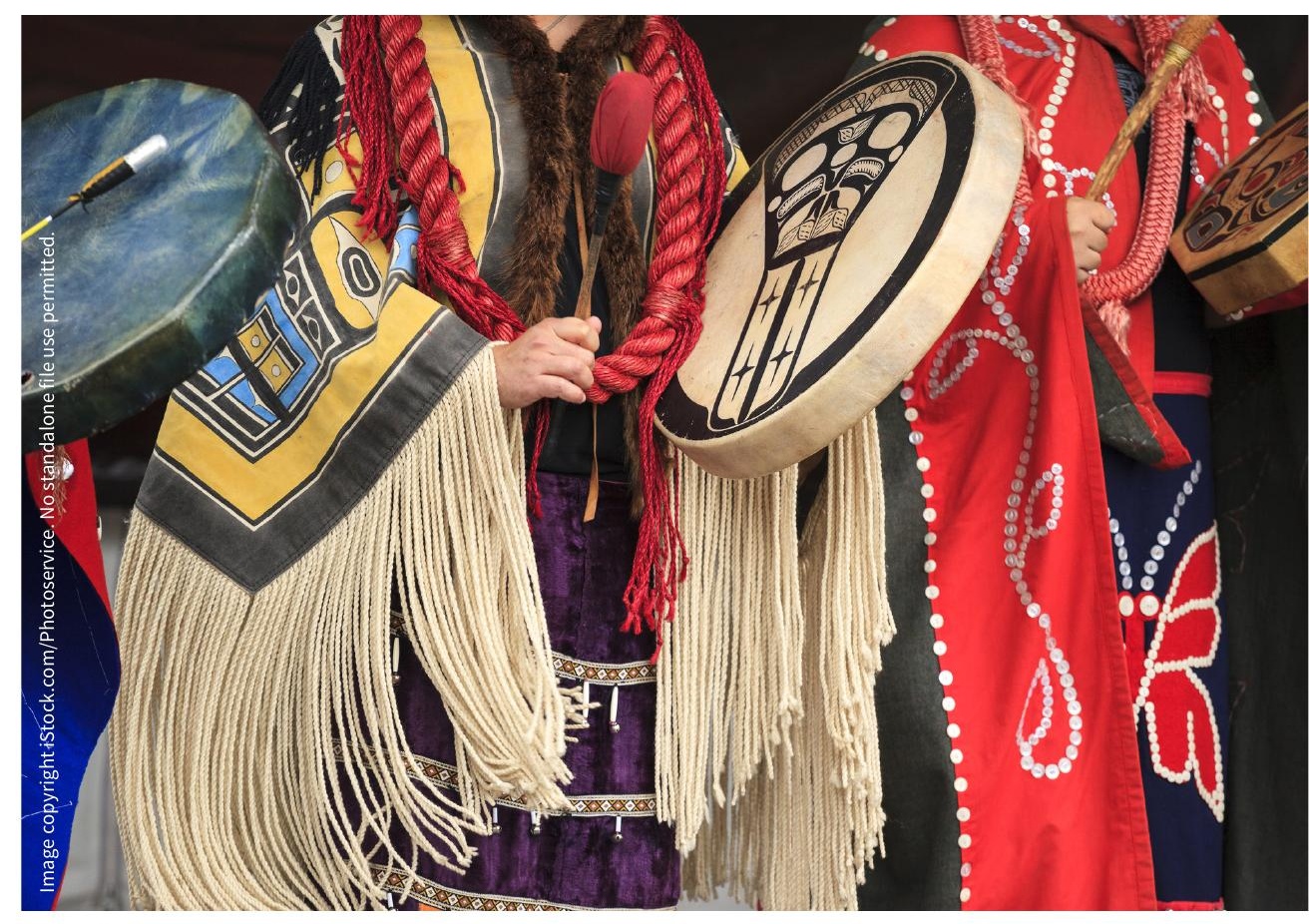

Sharing power and resources, and making space for cultural practices and arts, are crucial for healing, say experts.

based centre focused on Indigenous mental health. Launched at the Centre for Addiction and Mental Health in Toronto in November, the centre aims to improve Indigenous health outcomes through research, training and care that bring together traditional knowledge and clinical expertise. Patients can choose to receive traditional healing or clinical care or a combination of both. Linklater said it's an example of how health systems can be culturally relevant and collaborative at their core, rather than as an afterthought.

One of the biggest challenges to designing inclusive health systems is "making sure there are adequate resources dedicated to build appropriate care, programs and services," Linklater said. "In the case of Shkaabe Makwa, it was making sure CAMH dedicated core hospital resources to hire Indigenous leadership. It all comes from having a commitment from people who are open to new ways of providing care."

Earmarking core hospital funding for reconciliation efforts - in addition to funding change through envelopes for Indigenous communities - sends a message about an institution's priorities. "It's important to be able to say as a system... cultural safety is an absolutely critical part of health care service delivery."

Linklater and other presenters at the conference emphasized the importance 
of Indigenous representation at all levels - from the frontlines to leadership.

Denise Baldwin, a Black-Anishinaabe health promoter at Toronto's South Riverdale Community Health Centre, said hiring Indigenous harm reduction workers, including in leadership roles, built trust with the community the site serves. Les Harper, a Cree harm reduction worker and artist, also created artwork to make the clinic more welcoming.

A recent report by the Canadian AIDS Treatment Information Exchange likewise identified self-determination and making space for cultural practices and arts among the critical elements of successful Indigenous wellness programs.
In the past few years, some hospitals have started to provide access to elders and traditional healing. But according to Vanessa Ambtman-Smith, a Western University doctoral candidate of Nêhiyaw-Métis ancestry, there needs to be an intentional effort to hire Indigenous people in leadership positions to drive change at all levels of institutions.

Non-Indigenous leaders must also share responsibility for reconciliation, she said. "We can't have reconciliation with non-Indigenous people without having that leadership brought into the fold."

Linklater noted how meaningful it was to have CAMH's executive leaders participate in a sweat lodge ceremony on the ceremony grounds the hospital built. "Prior to the sweat lodge, I felt like they were supporting the work we were doing, but once they went in the sweat lodge, it shifted things. I really felt that they began to walk the path with us, and we are all in this together," she said.

\section{Diana Duong, CMAJ}

Content licence: This is an Open Access article distributed in accordance with the terms of the Creative Commons Attribution (CC BY-NC-ND 4.0) licence, which permits use, distribution and reproduction in any medium, provided that the original publication is properly cited, the use is noncommercial (i.e., research or educational use), and no modifications or adaptations are made. See: https://creativecommons.org/ licenses/by-nc-nd/4.0/ 